\title{
Lei determinadora do fôro competente para o inventário e partilha dos bens imóveis deixa- dos no Brasil por estrangeiro falecido no exterior
}

\section{Antônio Chaves}

Livre Docente de Direito Internacional Privado e de Direito Civil na Faculdade de Direito da Universidade de São Paulo.

Os dispositivos da lei pátria determinadores do fôro competente para o processamento de inventário podem dar origem a um curioso conflito não apenas de leis no espaço e no tempo, mas também, pelo menos aparentemente, nos seus diferentes graus hierárquicos, e até entre normas do mesmo diploma legal.

É o que ocorre com relação ao art. $10, \S 1 .^{\circ}$, da Lei de Introdução ao Código Civil, e ao art. 165 da Constituição Federal entre si e postos em confronto com o art. $12, \S 1 .^{\circ}$ da mesma Lei de Introdução e com o art. 135, $\S 1 .^{\circ}$ do Código de Processo Civil, dando margem a dúvidas e controvérsias que, através dos pronunciamentos da jurisprudência, revelam um ponto de atrito que merece estudo.

Imigrantes idosos, depois de terem amealhado aqui sua fortuna, fazem freqüentemente uma viagem aos pagos nativos, para reverem paragens da sua infância ou mocidade, ou pessoas que julgam ai permaneçam.

Uns têm intenção de voltar logo e lá se vão deixando ficar anos a fio, muitas vêzes contra a sua vontade, retidos pelo cansaço, pela desilusão, pela necessidade de se submeterem a cuidados ou operações médicas; outros se ins- 
talam em caráter definitivo, adquirem casa, fixam residência, para depois perceberem que não mais se acomodam ao antigo ambiente, deixando-se vencer pela vontade de regressar; nem faltam os que, combatidos por senfimentos opostos, não saibam sequer se querem ficar ou voltàr.

$\mathrm{Na}$ hipótese de virem a falecer, deixando bens imóveis no Brasil, qual a lei que deverá determinar o fôro competente para o inventário e a partilha?

Afirma-se que a matéria será regulada pela lei do domicílio.

Mas, além da dificuldade de fixá-lo em muitos casos, cumpre verificar se é essa, realmente, a vontade do legislador.

Lembremos, num rápido retrospecto, ter vigorado o princípio de que a sucessão legítima ou testamentária se regia pela lei nacional do falecido: apenas na hipótese de ser êste casado com brasileira, ou ter deixado filhos brasileiros, determinava a art. 14 da antiga Lei de Introdução que ficariam sujeitos à lei brasileira.

Transcrevendo o dispositivo, aditou a Constituição Federal de 1934, no art. 134, reproduzido na de 1937, a ressalva de lhes ser mais favorável o estatuto do "de cujus".

Passando a adotar o sistema do domicílio, o art. $10 \mathrm{da}$ nova Lei de Introdução dispôs que a sucessão por morte ou por ausência passaria a obedecer à lei do país em que era domiciliado o defunto ou o desaparecido, qualquer que seja a natureza e a situação dos bens.

Registra o § único exceção apenas relativa à vocação para suceder em bens de estrangeiros situados no Brasil, a ser regulada pela lei brasileira em benefício do cônjuge brasileiro e dos filhos do casal, sempre que lhes seja mais favorável a lei do domicílio.

Modificação ligeira, mas fundamental do art. $165 \mathrm{da}$ Constituição de 1946 substituiu a referência à lei do domicílio do "de cujus" pela da sua lei nacional, reiterando, como observa Oscar Tenório, o princípio da lei nacional do "de cujus", sem querer apegar-se ao princípio da lei domiciliar. 
A importância e a complexidade da matéria de um lado, e, de outro, a substituição dos princípios norteadores da lei nacional pela do domicílio, e novamente pela lei nacional com os conseqüentes reajustamentos ainda não definitivamente assentados, levantam incertezas que não podem ser dirimidas sem levar em conta a ponderação de Amílcar de Castro: o art. 14 da antiga Lei de Introdução e os arts. 134 e 152 respectivamente das Constituiçőes de 1934 e 1937 visavam a sucessão aberta no Brasil, ao passo que $o$ art. $10 \S 1 .^{\circ}$ da nova Lei de Introdução começou a focalizar a sucessão aberta no estrangeiro, inventário e partilha feitos no estrangeiro, por ser lá domiciliado o de cujus: fôsse êle domiciliado no Brasil e aqui se houvesse de fazer o inventário e partilha do espólio, a disposição seria inútil, uma vez que só a lei brasileira seria mesmo aplicável, a título de Iei do domicílio do finado.

Redigido como foi, acrescenta, o art. 165 da Constituição de 1946 , derrogando o art. $10 \& 1 .^{\circ}$ da nova Lei'de Introdução não se refere apenas a inventário e partilha feitos em jurisdição estrangeira, pois se pode haver lei na-. cional do de cujus mais favorável do que a brasilef́ra ao cônjuge e filhos brasileiros, não há razão para que se li-mite o benefício à hipótese de ser a sucessão aberta no estrangeiro, e sim também deve ser concedido quando a sucessão seja aberta no Brasil.

As hesitações decorrem da dificuldade de extremar o. conceito do domicílio do da morada.

"A morada transitória da pessoa natural em outro lugar" - decidiu o Tribunal de Justiça do Distrito Federal, “Diário da Justiça" de 27.3.1948, pág. 1046 — "não altera o fôro domiciliar, que é o do lugar onde ela estabelece sua residência com ânimo definitivo."

$O$ fato de ter o falecido terminado seus dias em Portugal, na Itália, na Espanha, após ter aí permanecido alguns anos, não é, na verdade, prova bastante de transferência de domicílio com ânimo definitivo.

Nem a essa conclusão é possível chegar-se por ter êle, antes de partir, liquidado seus negócios. Trata-se de cau- 
tela elementar e corrente, por parte de quem se disponha a uma viagem prolongada.

Sôbre essas circunstâncias de caráter secundário prevalece a de ter deixado aqui o seu patrimônio, o túmulo de seus entes queridos, parentes, círculo de amizades, interêsses de tôda sorte.

Ressaltando a circunstância de que basta a pessoa morrer em viagem de recreio ou de guerra em país estrangeiro para que a partilha se faça em condições imprevistas, bem diferentes das que eram esperadas pelo defunto e pelos herdeiros, obtempera o catedrático da Faculdade de Dĩreito da Universidade de Minas Gerais que a doutrina que recomenda o lugar onde haja falecido o de cujus e mantém a unidade de sucessão, constitui verdadeira loteria.

Não têm, apezar disso, faltado julgados no sentido de que o inventário e partilha dos bens devam ser processados no último domicílio do de cujus, embora seja no estrangeiro e os bens estejam situados no Brasil, procedendo-se aqui apenas à avaliação para fins fiscais.

Enumerando outros arestos análogos, critica-os o prof. Washington de Barros Monteiro, encarecendo que, nos têrmos do art. 135, $\S 1 .^{\circ}$ do Código de Processo Civil, se o óbito tiver ocorrido no estrangeiro, tornar-se-á competente o fôro do último domicílio do de cujus no Brasil.

$E$ assenta a questão na sua verdadeira base ao encarecer que o fato de haver o de cujus falecido em outro país, onde era domiciliado, não impede a abertura de seu inventário no Brasil, nos precisos têrmos da mencionåda lei adjetiva, cumprindo apenas ao juiz abster-se de partilhar bens situados no estrangeiro.

A norma do art. 10 "caput" da nova Lei de Introdução ao Código Civil procura, como é sabido, tornar efetiva a teoria unitária de SAvigny, que tantas dificuldades tem encontrado em sua aplicação prática.

1. Revista dos Tribunais, $186 / 270,193 / 381$.

2. Revista dos Tribunais, 191/761, 184/255, $176 / 369$. 
O alevantado propósito teórico do nosso legislador resultou numa proposição tècnicamente errônea e pràticamente contraproducente.

Tècnicamente errônea porque não podíamos, no âmbito internacional, impor diretrizes a país estrangeiro.

Sentiu-o Amílcar de Castro ao ponderar, criticando o art. 165 da Constituição, que pela jurisdição estrangeira será observado o direito internacional privado estrangeiro, e êste pode não manter como circunstância de conexão para a vocação hereditária a nacionalidade do "de cujus", sim o domicílio, ou mesmo o lugar de situação dos bens.

Claro que ao legislador pátrio incumbe apenas ditar normas aos que estejam sujeitos às suas determinações, nunca invadir a seara do legislador estrangeiro.

Êste, ou emanou disposição análoga, e a nossa não passará de um truísmo, - ou terá traçado orientação diferente, e, no estrangeiro, a determinação da lei pátria será letra morta.

Se o seu objetivo era evitar os efeitos da devolução, deveria limitar-se a declarar não aceitar a remissão por parte do legislador estrangeiro à nossa própria lei.

Pràticamente contraproducente porque contraria não sòmente outro preceito da Lei de Introdução (art. $12, \S 1^{\circ}$ ), como o espírito da legislação pátria, inspirada em cunho acentuadamente nacionalista, manifestando um zêlo e um cuidado que não se cinge apenas ao cônjuge brasileiro e aos filhos do casal.

Esse é apenas uma das manifestações de uma política legislativa que em centenas de atos e decretos, desde os tempos mais remotos da nossa nacionalidade, acompanhando o secular desenrolar-se de espisódios históricos, procura, de um lado, incorporar à comunidade os elementos alienigenas úteis, predendo-os por laços de afinidades morais e espirituais, e, de outro lado, preservar a nossa estrutura política e evitar a perigosa dispersão dos recursos patrimoniais de maior valia. 
É a preocupação constante, inexaurível, que se revela em mil e uma manifestações diferentes, de salvaguardar a segurança nacional, vedando aos estrangeiros o acesso aos cargos políticos e públicos; de ditar normas regulamentadoras das atividades e a participação nos capitais da imprensa, do rádio, do cinema, da televisão; de proteger as faixas de fronteira, os terrenos de marinha e marginais dos rios navegáveis contra a excessiva influência dos alienigenas, de evitar assessoramentos nas atividades econômicas, pela nacionalização do comércio da navegação aérea e marítima, dos estalecimentos bancários, das operações de seguros privados e das sociedades de capitalização; de garantir os recursos naturais, através nacionalização de minas, jazidas, quedas de água, materiais estratégicos, etc.

A tudo isso contrasta o art. 10 "caput" da Lei de Introdução quando manda se obedeça à lei do país em que era domiciliado o defunto para regulamentar sua sucessão mesmo que seus bens imóveis estejam situados no Brasil.

$\mathrm{E}$ a quem veríamos aquinhoados por tão extraordinário favor? Súditos, muitas vêzes, de países que não nos concedem a menor reciprocidade, que ciumentamente detêm os bens imóveis, evitando caiam em mãos de estrangeiros.

O dispositivo inspira-se no art. $8 .^{\circ}$ do título preliminar do antigo Código Civil italiano, que tantas recriminações tem levantado, a ponto de GABBA sustentar sua inaplicabilidade, afirmando que ao lado e acima da interpretação literal encontra-se a interpretação lógica, à qual, em caso concreto, é preciso ater-se de preferência, repugnando àquela, no direito internacional, a princípios jurídicos indiscutiveis tanto na ordem teórica como na ordem prática, primeiro entre êstes a independência dos Estados.

Abona o ponto de vista Prospero Fedozzi, para quem a norma deve ser considerada um lapsus mentis do legislador italiano "e considerarsi come non scritta, essendo in pari tempo inammissibile in teoria e impossibile nella pratica". 
O princípio foi abandonado pelo novo Codice Civile, que, coerente com a sua orientação, preferiu à regulamentação de acôrdo com a lei da situação dos bens, o da nacionalidade do de cujus por ocasião da sua morte, onde quer que se encontrem os bens ${ }^{3}$.

Se repulsa tão categórica mereceu o dispositivo em país de emigração, como a Itália, cuja política legislativa procura prender seus súditos pelo "jus sanguinis", como poderíamos acolhê-lo nós, que temos interêsses opostos, orientados por princípio antagônico, com tendência, mentalidade e necessidades díspares? Como admitir o sumárı cancelamento de todo êsse esfôrço consubstanciado em minudentes, exaustivas, terminantes manifestações legislativas, e obedecer a lei estrangeira em casos que se opõem tão flagrantemente aos princípios básicos da nossa estrutura jurídica?

Por amor a princípios teóricos não é possível sacrificar interêsses bem mais imediatos!

Não se pode deixar de reconhecer que, para o caso específico do Brasil, os conceitos de GabBa se afinam com a nossa realidade social: o art. 10, "caput" da Lei de Introdução precisa permanecer ilhado: como o peninsular, também o nosso legislador transladou para o âmbito rigoroso de uma afirmação legislativa um daqueles cânones gerais de direito internacional privado que nem sequer têm o mérito de estar suficientemente sedimentado através das indispensáveis convenções internacionais sôbre as quais possa repousar sua eficácia.

Encarece Amílcar dE Castro (e a crítica também se aplica ao dispositivo citado do Código Civil italiano) que é justamente na hipótese de se abrir a sucessão no estrangeiro que mais incompreensível se torna o art. 165 da Constituição, que qualifica de infeliz, merecedor das mesmas censuras feitas ao art. 14 da antigá Introdução.

Evidentemente, pela jurisdição estrangeira será observado o direito internacional privado estrangeiro, e êste pode

3. Art. 23 disp. prel. 
não manter como circunstância de conexão para a vocação hereditária a nacionalidade do de cujus sim o domicílio, ou mesmo o lugar de situação dos bens.

"A quê virá, pois, aquela referência à lei nacional? E, se aberta a sucessão no estrangeiro, fôr aplicada, não a lei nacional do de cujus, mas a lei de seu domicílio, e esta fôr mais favorável ao cônjuge e aos filhos brasileiros do que a lei nacional do de cujus?

Se o art. 165 da Constituição só se aplicasse a sucessões abertas no estrangeiro, — remata —, seria preferivel que sua referência fôsse a "lei reguladora da sucessão", em lugar de o ser a "lei nacional do de cujus".

Haroldo Valadão, em seu minucioso e erudito estudo sôbre "A Unidade ou Pluralidade da Sucessão e do Inventário e Partilha, no Direito Internacional Privado" 4, salienta que um dos maiores obstáculos à concretização da norma da universalidade da sucessão nas relações internacionais, é o que decorre do princípio geralmente aceito, de que a competência judiciária para decidir sôbre bens, particularmente imóveis, é privativa dos tribunais do Estado da respectiva situação.

Cita a lição de Alberto dos Reis: "o bom senso aconselha que os tribunais de cada país, em caso de conflito, se limitem a inventariar e partilhar os bens deixados no território nacional."

Uma coisa é, pois, o princípio, outra sua atuação prática.

Adverte que se nos outros paises onde se acham situados os bens da herança, não se adota o nossơ critério domiciliar unitarista e universalista, mas se observam outròs preceitos de direito internacional privado sucessório, a regra geral brasileira falha novamente e será forçada a excepcionar em favor de alguns daquêles preceitos da "lex

4. Revista dos Tribunais, vol. 204, págs. 3 e segs. 
rei sitae", da lei da nacionalidade, da lex fori (ordem pública) do próprio domicilio no estrangeiro se conceituado diferentemente da definição brasileira, etc..

“Então o verdadeiro critério é também aqui proceder qual nos outros casos, constitucional e legais, em que não se pode aplicar aquela regra geral, isto é, proceder a inventário autônomo no Brasil e para os bens daqui, se no lugar da situação dos outros bens fôr diversa, o que será a hipótese corrente, a regra de direito internacional privado."

Fedozzr, não justificando embora o art. $8 .^{\circ}$ do antigo "Titolo Preliminare", opunha-se aos conceitos de GabBa, demonstrando, em página memorável, que ao juiz não é lícito, a qualquer pretexto, deixar de aplicar a lei expressa.

A situação, entre nós, é porém diferente: não violaremos a lei deixando de aplicar a sua norma, pois socorrem-nos outros dispositivos, que se harmonizam perfeitamente com a orientação certa.

Pelo art. $12, \S 10^{\circ}$ da Lei de Introdução só à autoridade judiciária brasileira compete conhecer das ações relativas a imóveis situados no Brasil.

Aí está proclamada a competência privativa e exclusiva dos tribunais brasileiros para as ações relativas a imóveis situados no Brasil, pois a lei não se restringiu às ações reais sôbre imóveis, abrangendo, portanto, quaisquer litígios, quaisquer controvérsias, as ações mistas, as divisórias, os inventários e partilhas de bens imóveis situados no território nacional ${ }^{5}$.

E pelo art. 135, § $1 .^{\circ}$ do Código de Processo Civil, se o óbito houver ocorrido no estrangeiro, será competente para o inventário, a partilha e tôdas as ações relativas à herança, o fôro do último domicílio do "de cujus" no Brasil.

5. Frladelfo Azevedo, Um Triênio de Judicatura, I, pág. 151. 
Ai está reconhecido que mesmo que o falecimento ocorra além fronteira, aqui deverá ser feito o inventário e dada a partilha.

Os comentaristas ao Código de Processo Civil não estabelecem qualquer ressalva ou reserva no que diz respeito a uma possível influência do art. 10 "caput" da Lei de Introdução sôbre a norma processual.

Para de Plácido e Silva a regra prevalece, mesmo que o falecido tenha mudado residência para o estrangeiro, porquanto a disposição do art. $135 \S 10^{\circ}$ do Código de Processo Civil não abre exceções.

Menos axiomático não é J. M. de Carvalho Santos: "Em qualquer hipótese, prevalece a regra geral. Competente para o inventário e partilha é o juízo do último domicílio do de cujus no Brasil."

A jurisprudência pátria não se firmou ainda em caráter definitivo, e se existem manifestações como as inicialmente citadas, outras há, em sentido contrário.

Haroldo Valadão, no trabalho mencionado, faz ligeira referência ao caso Paulo Dorsa. Localizamos o ven. acórdão do E. Supremo Trìbunal Federal, que é de 15.10.1947. conflito de jurisdição n. $^{\circ} 1.685 .{ }^{6}$

Nele salienta o relator, Ministro Lafayette de Andrade, acompanhado à unanimidade, que o morto sempre havia residido em Cuiabá, onde mantinha negócios, fazendo parte de uma firma comercial cujas atividades cessaram em 1924.

Dessa cidade havia partido com destino a Nápoles, em 1926, não mais regressando ao Brasil, deixando no Estado de Mato Grosso bens imóveis, além de haveres da antiga firma comercial.

"Todos êsses fatos deixam ver claro a competência daquele Juízo (de Cuiabá), o que aliás está conforme ao preceito legal: se o falecimento tiver ocorrido no estrangeiro, será competente o

6. Diário de Justiça da União de 25-6-1949, pg. 1533. 
fôro do último domicílio do de cujus ou sendo incerto êsse domicilio, o fôro da situação do imóvel."

Outro caso de conflito de jurisdição, também procedente de Cuiabá, é o n. 1 716, relativo a José Orlando, que estabeleceu seu domicílio naquela cidade, para onde emigrara ainda jovem, constituindo família e formando valioso patrimônio.

Falecendo porém na Itália, de onde era originário, mais uma vez aplicou o Pretório Excelso o art. 135, $\S 1 .^{\circ}$ do Código de Processo Civil para a determinação do juízo competente $^{7}$

Inscreve-se dentro dêsses rigorosos princípios ven. acórdão unânime da C. Quarta Câmara do E. Tribunal de Justiça do Estado, reconhecendo que o fato de ter o de cujus falecido em Portugal, onde se diz que era domiciliado, ainda que efetivamente se verificasse esta última circunstância, não constituiria óbice ao processamento do inventário no Brasil, nos precisos têrmos do art. $135, \S 10^{\circ}$ do Código de Processo Civil.

O inventário dos bens aqui deixados, sôbre não prejudicar direitos de quaisquer interessados, nenhuma mossa faria às disposições legais atinentes à espécie.

Teremos então prevalecimento de norma processual sôbre a da Lei de Introdução e sôbre o próprio preceito constitucional?

De modo algum. O dispositivo da Carta Magna apenas remete à lei brasileira que regule a vocação para suceder em bens de estrangeiros situados no Brasil, que fôr mais favorável ao cônjuge e aos filhos brasileiros do que a lei nacional do de cujus, ressalvando pois, a aplicabilidade desta lei na hipótese contrária.

7. Ven. acórdão de 23.6.1948, Diário da Justiça de 10.1.1950, pág. 175.

8. Rev. dos Tribunais $186 / 845$. 
O choque ocorreria entre a norma de Direito Internacional Privado e a de processo.

Mas uma vez que o contraste se nota entre os dois aludidos dispositivos da Lei de Introdução, o bom senso quue orienta o Código de Processo Civil prevalecerá não como uma imposição da norma dêste, e sim como conseqüência, pelo menos quanto aos bens imóveis, do predomínio que sôbre o art. 10, $1^{\circ}$ não pode deixar de exercer o art. 12, $\S 10^{\circ}$, que melhor se harmoniza com a legislação pátria $\mathrm{e}$ que é o único princípio que poderá ser observado enquanto a matéria não fôr regulamentada convenientemente por meio de convenções internacionais. 